\title{
Evaluation on the Potential of 18 Species of Indoor Plants to Reduce Particulate Matter
}

\author{
$\mathrm{Na}$ Ra Jeong ${ }^{1 *}$, Kwang Jin Kim² ${ }^{2}$ Ji Hye Yoon ${ }^{1}$, Seung Won Han ${ }^{1}$, and Soojin You ${ }^{3}$ \\ ${ }^{1}$ Researcher, Urban Agriculture Division, National Institute of Horticultural \& Herbal Science, RDA, Wanju 55365, South Korea \\ ${ }^{2}$ Senior researcher, Urban Agriculture Division, National Institute of Horticultural \& Herbal Science, RDA, Wanju 55365, South Korea \\ ${ }^{3}$ Postdoctoral researcherUrban Agriculture Division, National Institute of Horticultural \& Herbal Science, RDA, Wanju 55365, South Korea
}

\section{ABSTRACT}

Background and objective: The main objective of this study is to measure the amount of particulate matter (PM) reduction under different characteristics of leaves in 18 different species of indoor plants.

Methods: First, a particular amount of PM was added to the glass chambers $(0.9 \times 0.86 \times 1.3 \mathrm{~m})$ containing the indoor plant (height $=40 \pm 20 \mathrm{~cm}$ ), and the PM concentration were measured at 2-hour intervals. The experiment with the same conditions was conducted in the empty chamber as the control plot.

Results: The range of PM reduction per unit leaf area of 18 species of experimental plants was $3.3-286.2 \mu \mathrm{g} \cdot \mathrm{m}^{-2}$ leaf, total leaf area was 1,123-4,270 $\mathrm{cm}^{2}$, and leaf thickness was $0.14-0.80 \mathrm{~mm}$ and leaf size $2.27-234.47 \mathrm{~cm}^{2}$. As time passed, the concentration of PM decreased more in the chamber with plants than in the empty chamber. Among the 18 indoor plants, the ones with the greatest reduction in PM2.5 in 2 hours and 4 hours of exposure to PM2.5 were Pachira aquatica and Dieffenbachia amoena. As the exposure time of PM increased, the efficiency of reducing PM2.5 was higher in plants with medium-sized leaves than plants with large or small leaves. The effect of reducing PM2.5 was higher in linear leaves than round or lobed leaves. Plants with high total leaf area did not have advantage in reducing PM because the leaves were relatively small and there were many overlapping parts between leaves. In the correlation between leaf characteristics and PM 2.5 reductions, all leaf area and leaf thickness showed a negative and leaf size showed a positive correlation with PM reduction.

Conclusion: The PM reduction effect of plants with medium-sized leaves and long linear leaves was relatively high. Moreover, plants with a large total leaf area without overlapping leaves will have advantaged in reducing PM. Plants are effective in reducing PM, and leaf characteristics are an important factor that affects PM reduction.

Keywords: Dieffenbachia amoena, leaf characteristics, Pachira aquatica, particulate matter

\section{Introduction}

With the increasing concentrations of particulate matter $(\mathrm{PM})$ in the air and the announcement of its risk, there has been a sudden increase in research on PM, especially on its reduction. In particular, as people spend more time indoors, increasing efforts have been made to improve indoor air quality and remove PM. Indoor PM concentrations are increased by cooking, cleaning, and other indoor activ- ities, and also when outdoor air enters. Alternatives to reduce indoor PM include reducing generation of outdoor $\mathrm{PM}$, reducing the causes of indoor PM, and preventing inflow of outdoor PM (Cao et al., 2019). These alternatives may lower the indoor PM concentrations by inhibiting the generation, but there are limitations in removing PM that is already formed indoors. For an environmentally friendly and sustainable method, studies have been conducted on the capability of plants to remove PM in the air (Beckett

This paper was funded by the research project of Rural Development Administration (PJ013677012020).

Received: September 23, 2020, Revised: October 17, 2020, Accepted: October 18, 2020

First author: Na Ra Jeong, jnr202@korea.kr, (1) https://orcid.org/0000-0002-0235-1424

*Corresponding author: Na Ra Jeong, jnr202@korea.kr, (1) https://orcid.org/0000-0002-0235-1424 
et al., 1998; Nowak et al., 2013; Tong, et al., 2015; Tong, et al., 2016; Willis and Petrokofsky, 2017). Plants are known to remove heavy metal such as mercury and lead, sulfur dioxide, volatile organic compounds, and PM in the air (Liu et al., 2012; Kim et al., 2008). Plants reduce PM by adsorbing PM (Perini et al., 2017) or absorbing it through leaves (Shahid et al., 2017), or through PM on the leeward side of the vegetation(Liu et al., 2012).

Plants' capability to reduce PM varies greatly depending on not only vegetation density, plant type, and layout (Tong et al., 2016), but also the individual characteristics of plants. In particular, leaf characteristics such as leaf surface roughness, stomatal density and size, wax layer, hair, and trichomes are key factors that reduce PM (Qiu et al., 2009; Räsänen et al. 2013). Since these leaf characteristics are involved in deposition and dispersion of fine particles (Janhäll, 2015), they must be considered in studying the relationship between plants and reduction of PM.

Many studies have been conducted on the relationship between microscopic characteristics of plant leaves planted in urban streets and green spaces with high PM concentrations and the amount of adsorbed PM. There were also studies on the wax layer of plants and adsorption of PM, but the results varied among the researchers (Sæbø et al., 2012; Räsänen et al., 2013). Despite the different results, they all explained that microscopic characteristics of leaves affected reduction of PM. Previous studies provided results with focus on specific regions and the morphological characteristics of plants. These results were limited in terms of region and type of plants, thereby applied restrictively to other regions. To this end, there is a need for an accurate experimental approach to quantify the PM reduction efficiency by plants under controlled environmental conditions. To study the PM reduction effect of plants using indoor chambers, Cao et al. (2019) explained the applicability of Epipremnum aureum by experimenting with 6 species of indoor plants. Panyametheekul et al. (2016) analyzed the change in PM concentrations caused by indoor and artificial plants in closed chambers and explained the PM reduction effect by adsorption.

This study evaluated indoor plants' potential for reduction of PM, which is a contaminant, using an indoor chamber experiment with limited variables of the external environment.
In particular, this study analyzed the difference in PM removal efficiency according to type of plants and leaf characteristics such as leaf size, thickness, and shape.

\section{Research Methods}

\section{Plants used in the experiments}

Plants used in the experiments were selected with reference to a book on indoor plants and air purifying plants (Rurlal Development Admistration, 2014). We selected 18 species that are most commonly used and easily obtainable by consumers (Table 1). The plants were purchased in $10 \mathrm{~cm}$ pots, after which they were transplanted to dodecagonal pots with a diameter of $15 \mathrm{~cm}$ so that they have similar volume and raised in a glass greenhouse. They were put under acclimatation in the greenhouse with a similar environment as the experimental conditions for 2 weeks before they were used in the experiments. We prepared 4 plants with the same size and volume and used them interchangeably in each experiment, and the leaves were wiped after each experiment to remove PM so that there

Table 1. Plants used in the experiments

\begin{tabular}{cc}
\hline Family name & Scientific name \\
\hline Nephrolepidaceae & Nephrolepis exaltata 'Bostoniensis' \\
Polypodiaceae & Platycerium bifurcatum \\
Aspleniaceae & Asplenium antiquum \\
Aspleniaceae & Asplenium nidus \\
Podocarpaceae & Podocarpus macrophyllus \\
Pittosporaceae & Pittosporum tobira \\
Araliaceae & Schefflera arboricola 'Hong Kong' \\
Malvaceae & Pachira aquatica \\
Moraceae & Ficus benjamina \\
Moraceae & Ficus elastica \\
Myrsinaceae & Ardisiajaponica \\
Geranium & Pelargonium hortorum 'Golden Ears' \\
Ericaceae & Rhododendron brachycarpum \\
Araceae & Anthurium andraeanum \\
Araceae & Epipremnum aureum \\
Araceae & Dieffenbachia amoena \\
Araceae & Philodendron selloum \\
Araceae & Philodendron 'Congo' \\
\hline
\end{tabular}


is no effect on the next experiment.

\section{Method of the experiments}

To study the PM reduction effect of indoor plants, we conducted chamber experiments in a laboratory to control external environmental factors. The chambers (width $0.9 \mathrm{~m} \times$ length $0.86 \mathrm{~m} \times$ height $1.3 \mathrm{~m}$ ) were made to be completely sealed using glass and stainless steel. The laboratory where the chambers were placed maintained the temperature of $22^{\circ} \mathrm{C}$, and lighting was set up in the chambers to maintain consistent intensity of illumination throughout the experiment (1500 lux).

The experiment was conducted in the order of 1) scattering PM, 2) pumping PM into the chamber, and 3) measuring PM (Fig. 1). We put JIS TEST POWDERS1(JIS Z 8901, APPIE, Japan) into the acrylic chamber and injected air into it with an air gun so that the test powder is mixed with air. After 4 hours, PM was pumped into the experimental chamber with the plant until the PM2.5 concentration became $300 \mu \mathrm{g} \mathrm{m}^{-3}$. Then, PM concentrations in the experimental chamber at 2-hour intervals.

The experiment was conducted by putting one type of plant into the chamber, and the same experiment was conducted on an empty chamber at the same time to use it as the control plot. Five repeated experiments were conducted on each plant.

\section{Measurement items and method of investigation}

PM concentrations in the experimental chamber were measured using a PM measuring device (aerosol monitor,
Model 8533, TSI Inc., USA). After putting PM into the empty chamber, the concentration decreased down to less than half within 4 hours or less. This experiment measured the initial value, after 2 hours, and after 4 hours. PM is particulate and is deposited on the surface of the chamber by sedimentation due to gravity or diffusion by convection regardless of whether there are plants. When there are plants, PM is adsorbed on the surface of the chamber as well as the plants, indicating that the PM reduction by plants can be obtained by subtracting the amount adsorbed on the chamber from total amount of reduction. The amount adsorbed on the chamber was calculated with the measured values of the empty chamber. PM variation in the chamber was calculated by subtracting PM concentration after 4 hours from the initial concentration in the chamber, and the amount of PM reduced by the plant was calculated by subtracting PM variation of the empty chamber (control plot) from PM variation of the chamber with the plant. The amount of PM reduced by plants was analyzed based on unit leaf area $\left(1 \mathrm{~m}^{2}\right)$ and compared among the plants.

We measured total leaf area using a leaf area meter (LI-3000, LI-COR, USA) after separating the leaves from their stems. Then we randomly selected 5 leaves and measured the leaf size and leaf thickness using a caliper (ABSOLUTE Digimatic Caliper, Mitutoyo).

\section{Method of analysis}

The measured values were statistically analyzed using SPSS Package 25. We conducted a t-test to verify the significance of the experimental chamber and the empty chamber, and one-way ANOVA to determine the relation-

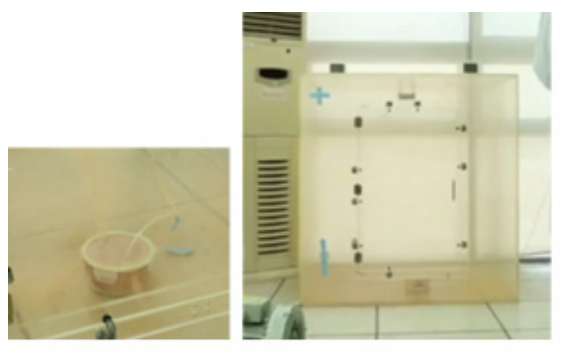

(a)

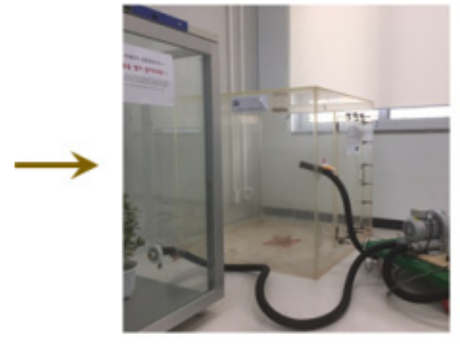

(b)
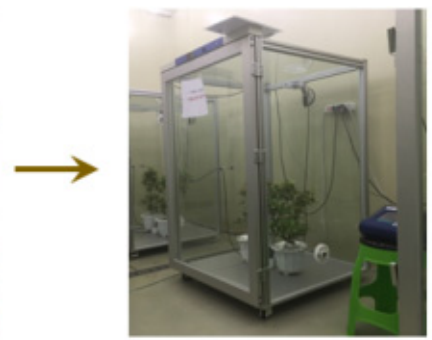

(c)

Fig. 1. The experiment was conducted in the order of a, b, c. (a) PM was scattered in an acrylic chamber $(1,800 \mathrm{~L})$. (b) After 4 hours, the scattered dust was pumped into the glass chamber. (c) The PM in the glass chamber was measured at two hourly interval. 
ship between PM reductions and morphological characteristics of each plant. Moreover, we classified the characteristics such as leaf thickness, size, and area by group and conducted correlation analysis, one-way ANOVA, and Duncan's new multiple range test (DMRT) to determine the relationship between these characteristics and reductions. We also conducted a linear regression analysis to determine the leaf characteristics of plants that affect PM reductions, and verified the significance of statistical analysis within 5\%.

\section{Results and Discussion}

\section{PM2.5 reduction effect of indoor plants}

As a result of monitoring the change in concentrations 2 hours and 4 hours after putting $300 \mu \mathrm{g} \cdot \mathrm{m}^{-3}$ of PM into the chamber with plants and the empty chamber, all chambers showed the similar trend in which PM2.5 concentrations decreased with time (Fig. 2). Assuming that the particles are spherical, the sedimentation speed by gravity is affected by the diameter of the particles, and thus heavier particles subside more quickly, whereas lighter particles float relatively longer in the air. The chamber with plants showed greater reductions than the empty chamber. While

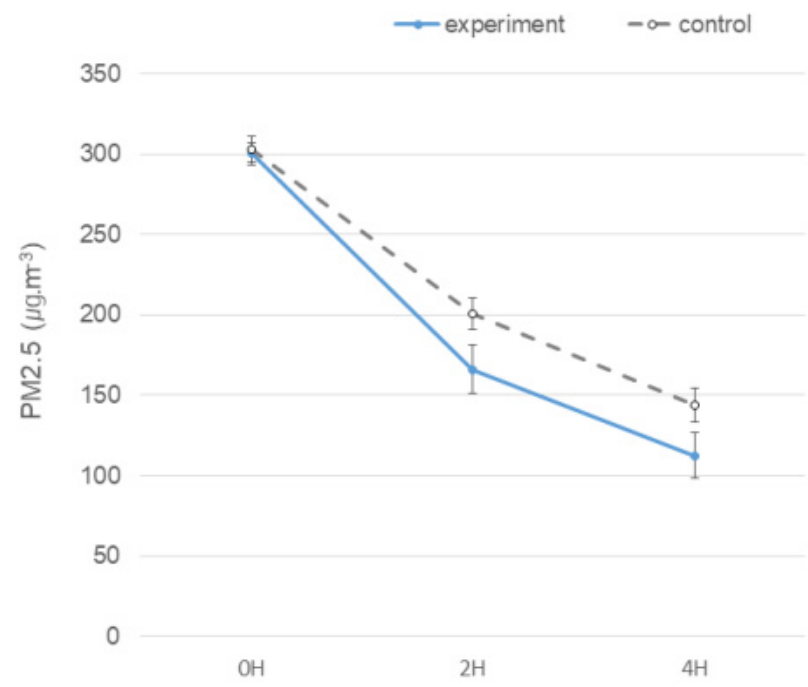

Fig. 2. Changes in the concentration of PM2.5 over time after adding fine dust to the plant chamber and empty chamber and expressed in $\mu \mathrm{g} \mathrm{m}^{-3}$. The plant chamber is the average of the results of five experiments of 18 plants $(N=90)$, and the error bar explains the standard deviation. the fine particles float in the chamber, some are sedimented and others are adsorbed on the plant leaves, thereby reducing PM concentrations within the chamber. This is because the plant takes up a certain volume of the chamber and thus reduces the distance between PM particles and the surface that can adsorb them (Ryu et al., 2019). This result is the same as the study by Lohr and Pearson-Mims (1996) which explained the effective decrease of PM when there are plants compared to the control plot without plants.

Since each plant has a different size, we calculated reductions based on $1 \mathrm{~m}^{2}$ of leaf area to compare PM reduction efficiency among the plants. There was a difference in reductions of PM2.5 after 2 hours and 4 hours depending on the plant, and this difference was also statistically significant (Table 2). Pachira aquatica and Dieffenbachia amoena showed reductions of 182.42 and $188.95 \mu \mathrm{g} \mathrm{m}$ leaf area respectively after 2 hours, showing remarkably higher levels of reductions than other plants. On the other hand, Pittosporum tobira, Anthurium andraeanum, Nephrolepis exaltata 'Bostoniensis', and Ficus elastica showed a reduction of less than $50 \mu \mathrm{g} \cdot \mathrm{m}^{-2}$ leaf area, which is relatively lower. Reductions after 4 hours were 163.89 for Pachira aquatica, 161.45 for Philodendron selloum, and 153.48 for Dieffenbachia amoena, which were high, and similar to after 2 hours, Pittosporum tobira, Pelargonium hortorum 'Golden Ears', Anthurium andraeanum, Nephrolepis exaltata 'Bostoniensis', and Ficus elastica tended to show low levels of reductions. Plants with medium-level reductions were Epipremnum aureum, Philodendron 'Congo', Platycerium bifurcatum, and Rhododendron brachycarpum. There was a certain difference in the ranking of reductions, but the reduction of each plant tended to be similar after 2 hours and 4 hours.

\section{Correlation between leaf characteristics and reduction effect}

To determine how the characteristics of leaves, which are an important part of plants, affect PM reduction efficiency, we classified the leaf characteristics into size, thickness, shape, and area to analyze the reduction efficiency and determine statistical significance. A correlation analysis with leaf size, thickness, area, and reduction as the vari- 
Table 2. Amount of PM2.5 reduction on leaves of 18 different species and expressed in $\mu \mathrm{g} \mathrm{m}^{-2}$ of leaf. A minimum of five experiments were performed per species

\begin{tabular}{|c|c|c|}
\hline \multirow{2}{*}{ species } & \multicolumn{2}{|c|}{ Amount of PM2.5 (mean $\pm \mathrm{SD})$ reduction $\left(\mu \mathrm{g} \mathrm{m}^{-2}\right.$ leaf) } \\
\hline & 2 hours after PM exposure & 4 hours after PM exposure \\
\hline Pittosporum tobira & $50.30 \pm 2.91 \quad \mathrm{~h}$ & $19.79 \pm 13.04 \mathrm{e}$ \\
\hline Ficus benjamina & $91.53 \pm 14.90$ defgh & $77.06 \pm 12.29$ bcde \\
\hline Pelargonium hortorum 'Golden Ears' & $60.30 \pm 17.25 \mathrm{gh}$ & $25.81 \pm 14.73 \mathrm{e}$ \\
\hline Anthurium andraeanum & $41.18 \pm 13.82 \mathrm{~h}$ & $37.98 \pm 7.06 \mathrm{~cd}$ \\
\hline Philodendron 'Congo' & $107.68 \pm 9.39 \quad$ cdefg & $110.18 \pm 27.26 \mathrm{abc}$ \\
\hline Epipremnum aureum & $119.59 \pm 68.32$ bcdef & $105.50 \pm 54.50$ abcd \\
\hline Pachira aquatica & $182.42 \pm 20.80$ a & $163.89 \pm 33.16$ a \\
\hline Schefflera arboricola 'Hong Kong' & $91.65 \pm 34.89$ defgh & $65.23 \pm 31.72$ cde \\
\hline Dieffenbachia amoena & $188.95 \pm 22.73 \mathrm{a}$ & $153.48 \pm 27.21 \mathrm{a}$ \\
\hline Platycerium bifurcatum & $124.07 \pm 35.71$ bcde & $138.91 \pm 23.56 \mathrm{ab}$ \\
\hline Philodendron selloum & $148.24 \pm 68.26 \mathrm{abc}$ & $161.45 \pm 146.59$ a \\
\hline Ardisia japonica & $140.40 \pm 38.36$ abcd & $100.74 \pm 41.47$ abcd \\
\hline Rhododendron brachycarpum & $112.39 \pm 37.36$ cdefg & $45.23 \pm 35.61$ cde \\
\hline Nephrolepis exaltata 'Bostoniensis' & $44.49 \pm 8.53 \quad h$ & $36.88 \pm 8.02 \quad \mathrm{de}$ \\
\hline Ficus elastica & $44.43 \pm 23.57 \mathrm{~h}$ & $38.33 \pm 20.16 \mathrm{de}$ \\
\hline Asplenium antiquum & $67.84 \pm 16.11 \mathrm{fgh}$ & $73.60 \pm 16.11$ bcde \\
\hline Asplenium nidus & $75.75 \pm 22.58$ efgh & $51.64 \pm 32.85 \mathrm{cde}$ \\
\hline Podocarpus macrophyllus & $165.46 \pm 8.99 \quad a b$ & $148.20 \pm 27.75 \mathrm{a}$ \\
\hline $\mathrm{F}(p$-value $)$ & $11.568(<.001)$ & $6.326(<.001)$ \\
\hline
\end{tabular}

Table 3. Correlation analysis between leaf characteristics and PM2.5 reduction

\begin{tabular}{ccc}
\hline Division & Reduction in 2 hours & Reduction in 4 hours \\
\hline Size of leaf & $0.260^{\mathrm{z}}(.036)^{\mathrm{y}}$ & $0.295(.018)$ \\
Thickness of leaf & $-0.232(.059)$ & $-0.115(.359)$ \\
Total leaf area & $-0.520(<.001)$ & $-0.392(.001)$ \\
\hline
\end{tabular}

${ }^{\mathrm{z}}$ Means the Pearson correlation coefficient, and ${ }^{\mathrm{y}}$ (the number in parentheses) means the $p$-value.

ables showed that leaf size had a positive correlation with PM2.5 reductions in 2 hours and 4 hours, while total leaf area had a negative correlation (Table 3 ). Leaf thickness was not significant within $5 \%$ but had a negative correlation with reduction in 2 hours within $10 \%$. Previous studies also explained that leaf characteristics such as leaf stoma, unit leaf area, and wax layer affect the level of deposition and dispersion of PM (Quit et al., 2009; Räsänen et al., 2013; Janhäll, 2015).

We analyzed the difference in reductions by classifying leaf size into five stages. Leaf size was classified based on the area of one leaf into $0-10 \mathrm{~cm}^{2}$ (Podocarpus macro- phyllus, Schefflera arboricola 'Hong Kong', Pelargonium hortorum 'Golden Ears', Pittosporum tobira), $20-40 \mathrm{~cm}^{2}$ (Ficus benjamina, Ardisia japonica, Epipremnum aureum, Rhododendron brachycarpum), $41-100 \mathrm{~cm}^{2}$ (Philodendron selloum, Pachira aquatica, Nephrolepis exaltata 'Bostoniensis', Asplenium nidus), 100 - $200 \mathrm{~cm}^{2}$ (Asplenium antiquum, Anthurium andraeanum, Ficus elastica, Philodendron 'Congo', Platycerium bifurcatum), and over $200 \mathrm{~cm}^{2}$ (Dieffenbachia amoena).

There was a statistically significant difference in PM2.5 reductions by group of leaf size. Dieffenbachia amoena with the biggest leaf size showed relatively more reduc- 
Table 4. Amount of PM2.5 reduction on leaves of 5 groups sorted by leaf size

\begin{tabular}{ccc}
\hline Group & \multicolumn{2}{c}{ Amount of PM2.5 (mean \pm SD) reduction $\left(\mu \mathrm{g} \mathrm{m} \mathrm{m}^{-2}\right.$ leaf $)$} \\
\cline { 2 - 3 } & 2 hours after PM exposure & 4 hours after PM exposure \\
\hline Leaf area 0-10 $\mathrm{cm}^{2}$ & $87.02 \pm 47.45 \mathrm{~b}^{\mathrm{z}}$ & $59.19 \pm 53.65 \mathrm{~b}$ \\
Leaf area 20-40 $\mathrm{cm}^{2}$ & $111.09 \pm 28.86 \mathrm{~b}$ & $84.78 \pm 36.09 \mathrm{~b}$ \\
Leaf area $41-100 \mathrm{~cm}^{2}$ & $112.83 \pm 66.68 \mathrm{~b}$ & $103.03 \pm 87.31 \mathrm{ab}$ \\
Leaf area 101-200 $\mathrm{cm}^{2}$ & $75.84 \pm 49.68 \mathrm{~b}$ & $75.82 \pm 47.74 \mathrm{~b}$ \\
Leaf area 200 $\mathrm{cm}^{2}$ over & $188.95 \pm 22.73 \mathrm{a}$ & $153.48 \pm 27.21 \mathrm{a}$ \\
\hline $\mathrm{F}(p$-value $)$ & $5.142(.001)$ & $2.646(.042)$ \\
\hline
\end{tabular}

${ }^{\mathrm{z}}$ Means followed by same letter within the column are not significantly different at $5 \%$ level.

Table 5. Amount of PM2.5 reduction on leaves of 4 groups sorted by leaf thickness

\begin{tabular}{ccc}
\hline \multirow{2}{*}{ Group } & \multicolumn{2}{c}{ Amount of PM2.5 (mean \pm SD) reduction $\left(\mu \mathrm{g} \mathrm{m}^{-2}\right.$ leaf $)$} \\
\cline { 2 - 3 } & 2 hours after PM exposure & 4 hours after PM exposure \\
\hline $0-0.20 \mathrm{~mm}$ & $112.99 \pm 58.11$ & $84.24 \pm 54.28$ \\
$0.21-0.35 \mathrm{~mm}$ & $117.52 \pm 65.64$ & $74.59 \pm 84.67$ \\
$0.36-0.50 \mathrm{~mm}$ & $95.19 \pm 48.97$ & $72.49 \pm 51.31$ \\
$0.60-0.80 \mathrm{~mm}$ & $74.69 \pm 42.06$ & $0.877(.458)$ \\
$\mathrm{F}(p$-value $)$ & $1.651(.187)$ & \\
\hline
\end{tabular}

tions after 2 hours and 4 hours than other plants. Except Dieffenbachia amoena, there was no statistically significant difference in reductions after 2 hours by leaf size among different plants. As for reductions after 4 hours, there was statistical significance between the $41-100 \mathrm{~cm}^{2}$ group and the over $200 \mathrm{~cm}^{2}$ group (Table 4). As the PM exposure time increased, medium-sized leaves relatively showed higher PM reduction efficiency than plants with big or small leaves. Weerakkody et al. (2018) also explained that PM reductions vary depending on leaf size, and small leaves showed greater PM reductions than big leaves.

Leaf thickness was classified into four stages for analysis: 0-0.20 mm (Nephrolepis exaltata 'Bostoniensis', Ardisia japonica, Ficus benjamina, Pachira aquatica), 0.21-0.35 mm (Philodendron selloum, Dieffenbachia amoena, Pelargonium hortorum 'Golden Ears', Asplenium antiquum), 0.36-0.50 mm (Rhododendron brachycarpum, Pittosporum tobira, Philodendron 'Congo', Schefflera arboricola 'Hong Kong', Epipremnum aureum, Anthurium andraeanum, Podocarpus macrophyllus), and 0.60-0.80 mm (Asplenium nidus, Platycerium bifurcatum, Ficus elastica).

PM2.5 reductions by leaf thickness were high in the
0.21-0.35 mm group at 117.52 and 101.59 after 2 hours and 4 hours, but there was no statistically significant difference from other groups (Table 5). Although there is no statistical significance, PM reduction levels were higher when the leaves were thinner than thicker. Leaf thickness is related to the weight of the wax layer, which is a plant characteristic that affects PM reduction; thus, an analysis must be conducted on the wax layer and PM reduction.

Leaf shape was divided into three types: round shape with no split edge or serra, vertically long and linear shape (Podocarpus macrophyllus), and irregular or lobed shape (Pelargonium hortorum 'Golden Ears', Nephrolepis exaltata 'Bostoniensis', Philodendron selloum, Platycerium bifurcatum). There is a statistically significant difference in PM2.5 reductions depending on leaf shape. Reduction levels after 2 hours and 4 hours were relatively higher in the linear shape, while other groups showed no statistical difference (Table 6). Round-leaf plants showed relatively greater reduction effect than lobed-leaf plants. Leonard et al. (2016) also showed similar results, proving that linear and lobed leaves retained more PM than oval leaves. Leaf shape is related to fluttering, which may separate the ad- 
Table 6. Amount of PM2.5 reduction on leaves of 3 groups sorted by leaf shape

\begin{tabular}{ccc}
\hline \multirow{2}{*}{ Group } & \multicolumn{2}{c}{ Amount of PM2.5 (mean $\pm \mathrm{SD})$ reduction $\left(\mu \mathrm{g} \mathrm{m}^{-2}\right.$ leaf $)$} \\
\cline { 2 - 3 } & 2 hours after PM exposure & 4 hours after PM exposure \\
\hline Round shape & $106.18 \pm 68.15 \mathrm{~b}^{\mathrm{z}}$ & $81.58 \pm 62.84 \mathrm{~b}$ \\
Lobed shape & $93.14 \pm 70.07 \mathrm{~b}$ & $75.82 \pm 83.20 \mathrm{~b}$ \\
Linear shape & $197.12 \pm 48.27 \mathrm{a}$ & $176.97 \pm 54.53 \mathrm{a}$ \\
$\mathrm{F}(p$-value $)$ & $5.829(.004)$ & $5.965(.003)$ \\
\hline
\end{tabular}

Note, Round shape includes elliptic, ovate, flabellate, and lobed shape means deeply indented margins and divided lateral lobes.

${ }^{\mathrm{z}}$ Means followed by same letter within the column are not significantly different at $5 \%$ level.

Table 7. Amount of PM2.5 reduction on leaves of 5 groups sorted by all leaf area

\begin{tabular}{ccc}
\hline \multirow{2}{*}{ Group } & \multicolumn{2}{c}{ Amount of PM2.5 (mean $\pm \mathrm{SD})$ reduction $\left(\mu \mathrm{g} \mathrm{m}^{-2}\right.$ leaf $)$} \\
\cline { 2 - 3 } & 2 hours after PM exposure & 4 hours after PM exposure \\
\hline $0-1300 \mathrm{~cm}^{2}$ & $133.05 \pm 48.25 \mathrm{a}^{\mathrm{z}}$ & $118.96 \pm 74.51 \mathrm{a}$ \\
$1301-1600 \mathrm{~cm}^{2}$ & $138.92 \pm 53.67 \mathrm{a}$ & $110.42 \pm 55.20 \mathrm{a}$ \\
$1900-2500 \mathrm{~cm}^{2}$ & $48.78 \pm 16.92 \mathrm{c}$ & $30.48 \pm 15.37 \mathrm{~b}$ \\
$2600-3000 \mathrm{~cm}^{2}$ & $90.94 \pm 20.43 \mathrm{~b}$ & $88.16 \pm 25.04 \mathrm{a}$ \\
$3500 \mathrm{~cm}^{2}$ over & $44.49 \pm 8.53 \mathrm{c}$ & $36.88 \pm 8.02 \mathrm{~b}$ \\
$\mathrm{~F}(p$-value $)$ & $16.844(<.001)$ & $8.995(<.001)$ \\
\hline
\end{tabular}

${ }^{\mathrm{z}}$ Means followed by same letter within the column are not significantly different at $5 \%$ level.

All leaf area is the sum of leaf areas of the experimental plant.

sorbed PM and thus affect the amount.

Alll leaf area of plants used in the experiment was classified into $1300 \mathrm{~cm}^{2}$ and below (Platycerium bifurcatum, Philodendron selloum, Philodendron 'Congo', Podocarpus macrophyllus, Rhododendron brachycarpum), 1301-1600 $\mathrm{cm}{ }^{2}$ (Pachira aquatica, Dieffenbachia amoena, Schefflera arboricola 'Hong Kong', Asplenium nidus, Ardisia japonica), 1900-2500 cm² (Pelargonium hortorum 'Golden Ears', Anthurium andraeanum, Ficus elastica, Pittosporum tobira), 2600-3000 cm (Asplenium antiquum, Epipremnum aureum, Ficus benjamina), and $3500 \mathrm{~cm}^{2}$ and above (Nephrolepis exaltata 'Bostoniensis'). The groups with narrow leaf areas showed relatively greater PM2.5 reductions after 2 hours and 4 hours, while broader leaf areas led to relatively lower levels of reduction (Table 7). There was a statistically significant difference among the leaf area groups. Since plants with broader leaves have relatively more area to adsorb PM, we may assume that they would have higher PM reduction efficiency. However, broader leaf area in a similar volume indicates that there are many overlapping leaves. When leaves overlap, the air flow is not smooth and thus have relative advantage in PM adsorption. Since there is a positive correlation between the leaf area index (LAI) of leaves and PM sedimentation (Liu et al., 2015), it is necessary to analyze LAI instead of leaf area to determine the relationship with PM reductions.

To determine the leaf characteristics that affect PM2.5 reductions, we conducted a regression analysis with reduction as the dependent variable, and leaf area, leaf size, leaf thickness, and leaf number as the independent variables. Three regression analysis formulas were derived after entering the variables by selection of stage (Table 8). Total leaf area was the characteristic that affected all three models. In other words, leaf area is an important variable in PM reduction by plants and has a negative correlation, and thus it must be taken into consideration. The model with high explanatory power had the adjusted $\mathrm{R}^{2}$ of 0.408 and selected total leaf area, leaf thickness, and leaf size as the variables. Leaf area and thickness had a negative effect, and leaf size had a positive effect. In other words, leaf characteristics turned out to be important factors affecting PM reduction. 
Table 8. Regression analysis between mean of PM2.5 reduction with leaf characteristics of the 18 indoor plants. The characteristics of leaves are the all area of the leaves (a), the size of the leaves (b), and the thickness of leaves (c)

\begin{tabular}{cccccccc}
\hline model & Factor & $\begin{array}{c}\text { Unstandardized } \\
\text { coefficients }\end{array}$ & $\begin{array}{c}\text { Standard } \\
\text { error }\end{array}$ & $\begin{array}{c}\text { Standardized } \\
\text { coefficients }\end{array}$ & $\mathrm{t}$ & $\mathrm{F}$ & adjusted R $^{2}$ \\
\hline \multirow{2}{*}{1} & Constant & 169.538 & 15.414 & & $10.999^{* *}$ & $23.316^{* *}$ & 0.259 \\
& Total area & -0.036 & 0.007 & -0.520 & $-4.829^{* *}$ & & \\
& Constant & 222.053 & 20.528 & & $10.817^{* *}$ & & \\
2 & All area(a) & -0.041 & 0.007 & -0.594 & $-5.870^{* *}$ & $20.041^{* *}$ & 0.373 \\
& Thickness(c) & -115.867 & 32.763 & -0.358 & $-3.536^{* *}$ & & \\
& Constant & 210.203 & 20.678 & & $10.166^{* *}$ & & \\
\multirow{2}{*}{3} & All area(a) & -0.039 & 0.007 & -0.567 & $-5.721^{* *}$ & \multirow{2}{*}{$15.723^{* *}$} & 0.408 \\
& Thickness(c) & -129.916 & 32.481 & -0.401 & $-4.000^{* *}$ & & \\
& Size(b) & 0.227 & 0.105 & 0.216 & $2.167^{*}$ & & \\
\hline
\end{tabular}

$* p<.05, * * p<.001$.
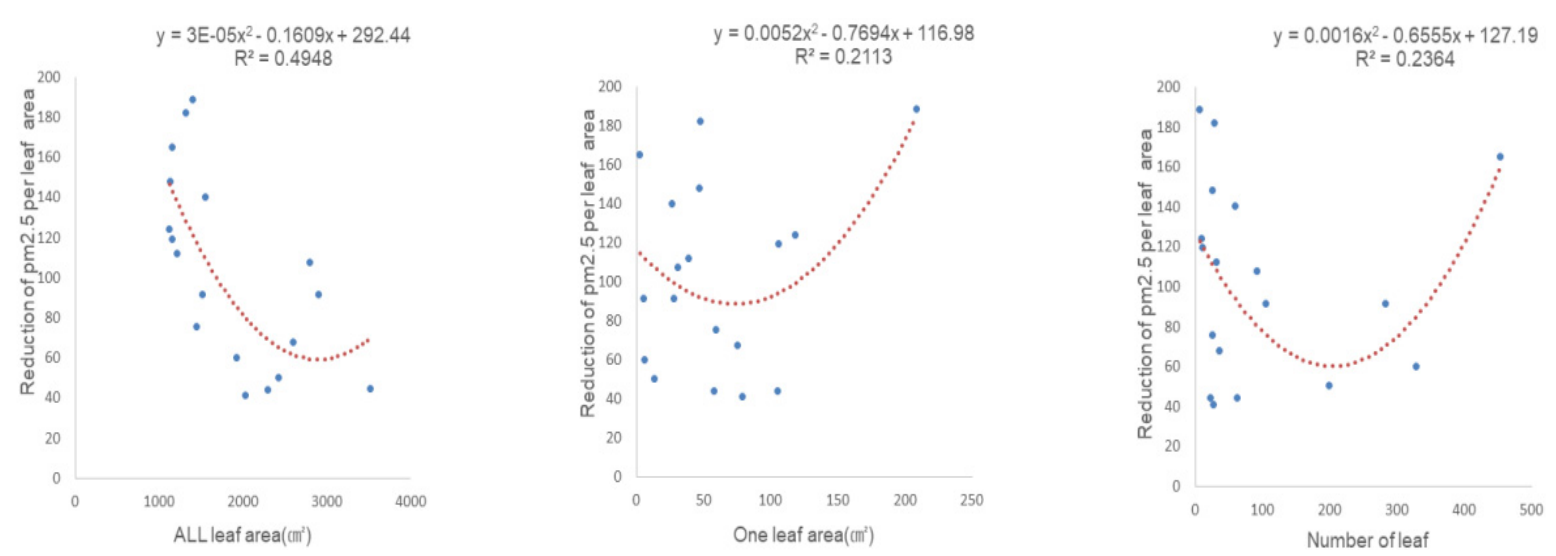

Fig. 3. Correlations between mean of PM2.5 reduction with leaf characteristics of the 18 indoor plants. The characteristics of leaves are the all area of the leaves, the size of the leaves, and the number of leaves from the left.

We analyzed through the regression analysis the factors of leaf characteristics that affect PM reduction and came up with scatter plots and second-order linear regression model to determine the relationship between each leaf characteristic and PM reduction (Fig. 3). The variable with high explanatory power was total leaf area, and PM2.5 reduction after 4 hours was the lowest when the leaf area was 2,682 $\mathrm{cm}^{2}$, showing a U-shape. In other words, adequate leaf area is required in PM reduction by indoor plants. Leaf number, although it does not have high explanatory power, also showed a U-shape. This similar result is due to the positive correlation between leaf number and leaf area. Medium-sized leaves had a low reduction effect, with one leaf size at $74 \mathrm{~cm}^{2}$, showing a U-shape. Previous studies also showed conflicting results in the reduction effect depending on leaf characteristics, which, compared to the results of this study, can be explained that there is high PM reduction effect when the leaves are either extremely big or small.

\section{Conclusion}

This study is to determine the PM reductions of 18 species of indoor plants and the difference in PM reduction efficiency according to leaf characteristics. PM concentrations decreased over time in the chamber with plants rather than in the empty chamber, which proved the effect of plants in reducing PM. Among the 18 species of plants, 
the ones showing highest levels of PM2.5 reductions in 2 hours and 4 hours were Pachira aquatica and Dieffenbachia amoena, indicating that they had higher PM2.5 reduction efficiency than other indoor plants. Plants with medium-sized leaves showed higher PM reduction efficiency in longer exposure time compared to those with big or small leaves. Long, linear leaves showed greater PM reduction effect than round or lobed leaves. Plants with big total leaf area have relatively small leaves and many overlapping leaves, and thus do not have advantage in PM reduction. However, for outdoor plants, there is a positive correlation between LAI and PM adsorption. Therefore, further research is needed on the correlation between the reduction effect of indoor plants and LAI rather than total leaf area. In the relationship between leaf characteristics and PM2.5 reductions, leaf area and leaf thickness have a negative effect, and leaf size has a positive effect. In other words, leaf characteristics of plants turned out to be an important factor that affects PM reduction. Further research must be conducted to determine PM reduction efficiency by generally considering the weight of the wax layer, existence of hair and trichome, structure of the leaf surface such as stoma, and morphological characteristics of leaves.

\section{References}

Beckett, K.P., P.H. Freer-Smith, and G. Taylor. 1998. Urban woodlands: Their role in reducing the effects of particulate pollution. Environ. Pollut. 99(3):347-360. https://doi.org/10.1016/S0269-7491(98)00016-5

Cao Y., F. Li, Y. Wang, Y. Yu, Z. Wang, X. Liu, and K. Ding. 2019. Assisted deposition of PM2.5 from indoor air by ornamental potted plants. Sustainability 11(9): 2546-2555. https://doi.org/10.3390/su11092546

Janhäll, S. 2015. Review on urban vegetation and particle air pollution - Deposition and dispersion. Atmos. Environ. 105:130-137. https://doi.org/10.1016/j.atmosenv.2015.0 1.052

Kim, K.J., M.J. Kil, J.S. Song, E.H. Yoo, K.C. Son, and S.J. Kays. 2008. Efficiency of volatile formaldehyde removal by indoor plants: Contribution of aerial plant parts versus the root zone. J. Am. Soc. Hortic. Sci., 133(4):
521-526. https://doi.org/10.21273/JASHS.133.4.521

Leonard, R.J., C. McArthur, and D.F. Hochuli. 2016. Particulate matter deposition on roadside plants and the importance of leaf trait combinations. Urban For. Urban Green. 20: 249-253. https://doi.org/10.1016/j.ufug.2016. 09.008 .

Liu, L., D. Guan, and M.R. Peart. 2012. The morphological structure of leaves and the dust-retaining capability of afforested plants in urban Guangzhou, South China. Environ. Sci. Pollut. Res. 19(8):3440-3449. https://doi.o $\mathrm{rg} / 10.1007 / \mathrm{s} 11356-012-0876-2$

Liu, X., X. Yu, and Z. Zhang. 2015. PM2.5 concentration differences between various forest types and its correlation with forest structure. Atmosphere 6(11):1801-1815. https://doi.org/10.3390/atmos6111801

Lohr, V.I. and Pearson-Mims, C.H. 1996. Particulate matter accumulation on horizontal surfaces in interiors: Influence of foliage plants. Atmospheric Environ. 30(14):2565-2568. https://doi.org/10.1016/1352-2310(95)00465-3

Nowak, D.J., S. Hirabayashi, A. Bodine, and R. Hoehn. 2013. Modeled PM2.5 removal by trees in ten U.S. cities and associated health effects. Environ. Pollut. 178:395-402. https://doi.org/10.1016/j.envpol.2013.03.050

Panyametheekul, S., T. Rattanapun, and M. Ongwandee. 2016. Ability of artificial and live houseplants to capture indoor particulate matter. Indoor Built Environ. 27(1): 121-128. https://doi.org/10.1177/1420326X16671016

Perini, K., M. Ottelé, S. Giulini, A. Magliocco, and E. Roccotiello. 2017. Quantification of fine dust deposition on different plant species in a vertical greening system. Ecol. Eng. 100:268-276. https://doi.org/10.1016/j.ecolen g.2016.12.032

Qiu, Y., D. Guan, W. Song, and K. Huang. 2009. Capture of heavy metals and sulfur by foliar dust in urban Huizhou, Guangdong Province, China. Chemosphere 75(4):447-452. https://doi.org/10.1016/j.chemosphere.2 008.12 .061

Räsänen, J.V., T. Holopainen, J. Joutsensaari, C. Ndam, P. Pasanen, Å. Rinnan, and M. Kivimäenpää. 2013. Effects of species-specific leaf characteristics and reduced water availability on fine particle capture efficiency of trees. Environ. Pollut. 183:64-70. https://d oi.org/10.1016/j.envpol.2013.05.015

Rurlal Development Admistration. 2014. Indoor air purify- 
ing plants. Rurlal Development Admistration. Wanju, Korea: Author.

Ryu, J., J.J. Kim, H. Byeon, T. Go, and S.J. Lee. 2019. Removal of fine particulate matter (PM2.5) via atmospheric humidity caused by evapotranspiration. Environ. Pollut. 245:253-259. https://doi.org/10.1016/j.envpol.20 18.11 .004

Sæbø, A., R. Popek, B. Nawrot, H.M. Hanslin, H. Gawronska, and S.W. Gawronski. 2012. Plant species differences in particulate matter accumulation on leaf surfaces. Sci. Total Environ. 427-428:347-354. https://doi.org/10.1016/j.scitotenv.2012.03.084

Shahid, M., C. Dumat, S. Khalid, E. Schreck, T. Xiong, and N.K. Niazi. 2017. Foliar heavy metal uptake, toxicity and detoxification in plants: A comparison of foliar and root metal uptake. J. Hazard. Mater. 325:36-58. https://doi.org/10.1016/j.jhazmat.2016.11.063
Tong, Z., T.H. Whitlow, A. Landers, and B. Flanner. 2016. A case study of air quality above an urban roof top vegetable farm. Environ. Pollut. 208:256-260. https://doi. org/10.1016/j.envpol.2015.07.006

Tong, Z., T.H. Whitlow, P.F. Macrae, A.J. Landers, and Y. Harada. 2015. Quantifying the effect of vegetation on near-road air quality using brief campaigns. Environ. Pollut. 201:141-149. https://doi.org/10.1016/j.envpol.20 15.02.026

Weerakkody, U., J.W. Dover, P. Mitchell, and K. Reiling. 2018. Evaluating the impact of individual 17 leaf traits on atmospheric particulate matter accumulation using natural and synthetic leaves. Urban For. Urban Green. 30:98-107. https://doi.org/10.1016/j.ufug.2018.01.001

Willis, K.J. and G. Petrokofsky. 2017. The natural capital of city trees. Science 356:374-376. https://doi.org/10.11 26/science.aam9724 